\title{
O currículo e a educação de jovens e adultos: espaço de poder-saber
}

\author{
Curriculum and education of young and adults: \\ the space of power-knowledge
}

\author{
Elizabeth Gottschalg RAIMANN
}

\begin{abstract}
RESUMO
O currículo estabelece quais conhecimentos priorizar em relação a outros, bem como qual a visão de mundo e de homem, e qual "verdade" proclamar. A teoria curricular dá sustentação epistemológica ao que o currículo irá efetivar através das políticas curriculares que, por sua vez, viabilizarão a proposta do currículo, por meio de ações e de documentos em nível macro e micro. Em sala de aula o currículo opera determinando papéis, relações entre professor e alunos, validam certos conhecimentos e outros não, incluem certos indivíduos, excluindo outros. Entendemos o currículo como uma trajetória que envolve toda a dinâmica na e para a escola, com fins a produzir identidades e subjetividades. Neste estudo, como objetivo, procuramos problematizar o campo do currículo, enfocando especificamente a Educação de Jovens e Adultos numa visão pós-crítica apontando algumas implicações para a mesma. Nesta perspectiva, a Educação de Jovens e Adultos passa a ser percebida como uma educação em termos de campo político cultural; um espaço de saber-poder que produz diferentes identidades.
\end{abstract}

Palavras-chave: currículo, educação de jovens e adultos, podersaber.

\begin{abstract}
The curriculum establishes some sort of knowledge to be priority respecting to others, such as the World view and Human view, and which "truth" it should proclaim. The curricular theory gives epistemological support whereat the curriculum will actualize through the curricular policies that, for its turn, will make viable the proposal of the curriculum, with actions and documents in macro and micro level. In the classroom the
\end{abstract}


curriculum operates by settling roles and relations between teacher and students, it validates certain knowledge in spite of others, and also it includes certain individuals while it excludes other ones. We understand the curriculum as a trajectory that involves the entire dynamic in and for the school, in order to produce identities and subjectivities. In this study, as an objective, we try to problematize the curriculum field, focusing specifically on the education of young and adults in a pos-critic view. In this perspective, the Education of Young and Adults begins to be perceived as an education in terms of cultural political field, a space of power-knowledge that produces different identities.

Index Terms: curriculum, education of young and adults, powerknowledge.

\section{Introdução}

O currículo estabelece quais conhecimentos priorizar em relação a outros, qual a visão de mundo e de homem e que "verdade" proclamar. A teoria curricular dará sustentação epistemológica à efetivação do currículo na educação básica através das políticas curriculares, que por sua vez viabilizarão a proposta do currículo por meio de ações e de documentos em nível macro e micro.

Nas discussões sobre as práticas educacionais, ao se proporem reformas e reestruturações, as questões de currículo aparecem como elementos centrais. Essas reformas propiciam um espaço de luta entre diferentes grupos dominantes. Esses grupos, por meio de discussões e pressões, procuram implementar suas idéias em torno dos diferentes significados sobre questões sociais e políticas. Desta forma, historicamente, essas idéias dominantes - visão eurocêntrica, do homem branco, da religião cristã, do mundo capitalista - permearam perspectivas educacionais no currículo escolar.

As políticas curriculares em nível macro autorizam certos grupos de especialistas em detrimento de outros, a exemplo do que afirma Silva (1999, p. 11): “[...] fabricam os objetos epistemológicos de que falam, por um 
léxico próprio [...] mecanismo altamente eficiente de instituição e de constituição do real". Além disso, atribuem ações e papéis específicos, geram diretrizes, guias curriculares, normas, grades, livros didáticos. Em nível micro, já em forma de currículo, operam em sala de aula determinandos papéis, relações entre professor e alunos, validam certos conhecimentos — mas outros não —, incluem certos indivíduos, excluindo outros (SILVA, 1999).

Nessa perspectiva, quando discutimos currículo como uma trajetória que envolve toda a dinâmica na e para a escola, com fins de produzir identidades e subjetividades, faz-se necessário situar de que posição teórica se fala, lembrando que, implicitamente, em tal posição encontram-se imbricadas determinadas visões de mundo e de homem.

Este trabalho pretende problematizar algumas questões referentes ao campo do currículo, enfocando especificamente a Educação de Jovens e Adultos numa visão pós-crítica, considerando as contribuições de Foucault. Pretende, também, apresentar os resultados de pesquisa realizada junto a uma classe de adultos, $1^{\circ}$ Segmento, na cidade de Itumbiara-GO, quanto ao uso do livro didático. E, por último, refletir sobre algumas possibilidades para essa modalidade de ensino a partir do referencial das teorias póscríticas.

\section{0 currículo numa visão pós-critica}

Se considerarmos as mudanças ocorridas no século $\mathrm{XX}$ nos diversos setores das esferas social, política, econômica e científica, propondo uma nova ordem social, não podemos deixar de considerar a possibilidade de que estamos passando por uma crise paradigmática.

Veríssimo (1997a) afirma que as mudanças apresentam elementos básicos para propor a pós-modernidade. O poder político e a cultura são redefinidos pela globalização. Assim como ocorre o deslocamento do poder de forma descentrada e sem território definido, as mudanças na natureza das 
forças de produção e os novos movimentos sociais se definem de forma crítica e contundente.

A educação, diante desse contexto, não fica imune às influências que circulam nos discursos e nas práticas atuais. A esfera educacional reflete e legitima o projeto de sociedade que é proposto nos diferentes momentos históricos.

Assim, como na época medieval tinha-se como base o modelo ontológico na educação, o modernismo tem suas bases no modelo firmado na razão iluminista, o qual prioriza a razão científica e a técnica. E a pósmodernidade, o que nos propõe?

O pensamento pós-moderno não acredita num projeto único para a sociedade, pois percebe a realidade de forma complexa. Com isso, abrem-se possibilidades até então desconhecidas, gerando inseguranças, uma vez que não estamos acostumados a lidar com incertezas, principalmente em educação.

Neste contexto, a educação encontra-se diante de um desafio. Faz-se necessária uma avaliação das propostas teórico-metodológicas tanto liberais quanto crítico-progressistas. Ambas com uma visão de relações binárias de bem e mal, oprimido e liberto, ingênuo e sábio, que em seus projetos educativos revelam o entendimento de educação como trabalho de conscientização por meio do conhecimento, levando o indivíduo ao esclarecimento, à libertação e à autonomia (VERÍSSIMO, 1997a).

$\mathrm{O}$ discurso pós-moderno procura dar outro enfoque à teoria educacional, levando em conta não mais o discurso totalizante, mas o discurso que considera a pluralidade. Considera também as diferenças de subjetividades e as variadas narrativas possibilitando outras leituras da realidade. Como seria, então, a proposta de currículo nesta perspectiva?

Segundo Silva (2001), não existe uma teoria de currículo, o que se apresenta são atitudes influenciadas pelas concepções pós-modernistas sobre o currículo. 
Sob esse ponto de vista, o currículo teria como característica observar "o processo de significação como basicamente indeterminado e instável [...] não sendo pré-existente, é cultural e socialmente produzido" (SILVA, 2001, p. 123). Dessa forma, o conhecimento passaria a ser examinado no sentido das opções feitas, considerando: por que este conhecimento e não aquele, a quem este conhecimento privilegia e por quê. Outras atitudes, presentes nessa linha de entendimento, seriam os questionamentos feitos quanto à noção de verdade e a concepção de sujeito. Quanto ao primeiro, o que se pretende não é saber o que é verdadeiro, mas por que se tornou verdadeiro. Interessa-se pelos significados transcendentais relativos à religião, à pátria, à política e às ciências presentes no currículo e pelas relações binárias presentes como masculino e feminino, branco e preto, científico e não-científico, heterossexual e homossexual, buscando sua desconstrução. No que se refere ao sujeito, problematiza-se a concepção humanista de sujeito e do sujeito consciente da educação emancipadora. Numa visão pós-modernista, a identidade é produzida baseada nos discursos e nos dispositivos presentes na sociedade. Silva (2001) argumenta que a perspectiva pós-crítica deve combinar com a teoria crítica contribuindo à compreensão mais ampla de currículo, passando a entender que currículo é uma questão de saber, identidade e poder.

A Educação de Jovens e Adultos, nesta perspectiva pós-crítica, sofreria uma mudança considerável. Em vez de buscarmos uma educação para a conscientização, passaríamos a ver a educação em termos de campo político-cultural.

Temos percebido até aqui que as diferentes propostas de Educação de Jovens e Adultos desenvolvidas por diversos segmentos, tanto governamentais quanto não-governamentais, têm se referenciado nas abordagens teórico-metodológicas de Paulo Freire. Em suas práticas educativas, tanto de alfabetização quanto na formação continuada, estes mesmos segmentos, por meio de um projeto emancipador de sociedade, têm 
buscado práticas pedagógicas que objetivam a conscientização dos alunos e a luta por seus direitos de cidadania, oportunizando sua inserção na sociedade atual (SOARES, 2001; ANPED, 2002).

O pensamento pós-crítico, referência para os movimentos sociais, estudos multiculturais e nos estudos de gênero (SILVA, 2001; COSTA, 1998) passa a perceber a educação, a pedagogia e o currículo como uma Teoria Cultural, campos de luta e conflito simbólicos, questionando conteúdos e a natureza do conhecimento veiculado (VERÍSSIMO, 1997b).

No segmento seguinte, problematizar-se-á o currículo presente na Educação de Jovens e Adultos com base no resultado de pesquisa junto a uma sala dessa modalidade de ensino.

\section{A sala de aula espaço de poder-saber}

Com o foco na Educação de Jovens e Adultos, em específico uma escola municipal da cidade de Itumbiara-GO que oferece o $1^{\circ}$ Segmento $1^{\mathrm{a}}$ à $4^{\mathrm{a}}$ séries do Ensino Fundamental - analisou-se a complexidade das

relações de poder-saber que, mediante práticas e discursos, produzem os alunos dessa modalidade de ensino, individualizando-os e sujeitando-os a si e à sociedade capitalista.

Como procedimento de pesquisa, utilizou-se a entrevista não estruturada junto à professora regente e a observação da sala de aula, analisando-se algumas práticas pedagógicas desenvolvidas, bem como a escolha e o uso do livro didático (LAVILLE; DIONNE, 1999).

A sala de aula, numa perspectiva foucaultiana, apresenta-se como um laboratório de poder, possibilitando a produção de discursos e de práticas para o campo da pedagogia. Os discursos produzidos, mediante a relação poder-saber, pretendem se instituir como regimes de verdade e são elaborados por meio de dispositivos disciplinares presentes na observação, na confissão, nas disciplinas, na utilização do espaço e do tempo escolar. Por meio de práticas pedagógicas como "repetir o dito mediante narrativas 
históricas, exposição de conhecimentos legitimados, autorizados e reproduzidos pelo ritual do cotidiano de aulas expositivas, estudos, provas, avaliações" (CARLOS, 2002, p. 110), desenvolvidas pelos professores em sala de aula, formular-se-ão discursos pedagógicos para a individualização dos indivíduos e, não menos, a sua sujeição.

Foucault (2001b, p.161) argumenta que "o indivíduo é sem dúvida o átomo fictício de uma representação 'ideológica da sociedade', mas é também uma realidade fabricada por essa tecnologia específica do poder que se chama de disciplina". Assim, esse indivíduo torna-se qual artefato fabricado pelas práticas discursivas, nas quais o campo da pedagogia se insere e, nesse sentido, o poder se torna produtivo, pois mediante seus dispositivos, procura levantar todo um conhecimento a respeito desse indivíduo para estabelecer "verdades" e contribuir para levar adiante um projeto de homem e de sociedade, ou seja, os fins da educação.

A escola da sociedade capitalista neoliberal é produzida por essa sociedade que redefine a sua educação em termos de mercado, ao mesmo tempo em que essa educação fabrica um tipo de indivíduo para atender a essa mesma sociedade.

Foucault ao tratar do poder e da formação da sociedade disciplinar menciona a arquitetura do Panóptico. Seu princípio está pautado no dispositivo disciplinador do olhar que induz a uma constante vigilância.

Além dessa estrutura arquitetônica, Foucault propõe um outro entendimento para o Panóptico. Esse seria "como máquina de fazer experiências, modificar o comportamento, treinar ou retreinar os indivíduos [...] tentar experiências pedagógicas" (FOUCAULT, 2001b, p. 168). Esse dispositivo de observação seria algo parecido com um laboratório de poder na produção de saber. Assim, o saber, por sua vez, re-alimentado pelo poder conduziria a essa relação poder-saber que produz discursos e sujeitos. 
Apontando para essa percepção é possível dizer que no interior da escola municipal pesquisada também existem mecanismos de controle similares e mais sutis.

O espaço da sala de aula semelhantemente à escola também está sob dispositivos disciplinares como o olhar, o exame, a classificação. A diferença está em que, além desses dispositivos, há uma tecnologia do eu, ou seja, o governo de si mesmo faz com que esse dispositivo seja mais incisivo sobre o corpo, passando a cada aluno a se auto-regular, se autodisciplinar. Essa autodisciplina se verifica no momento do trabalho em grupo, na partilha dos materiais didáticos, no sentar-se em círculo, ouvir e esperar a vez para falar.

Considerando as práticas pedagógicas, de modo geral, efetivadas em sala de aula, essas se estabelecem numa arena de luta e não existem práticas pedagógicas que sejam por si mesmas libertadoras ou repressivas (GORE, 2002). Como as relações de poder são circulantes, não localizadas, qualquer prática pode tornar-se um exercício de poder e qualquer prática é capaz de tornar-se fonte de resistência.

Na observação e análise das práticas desenvolvidas pela professora, e o uso do material didático-pedagógico utilizado, pode-se perceber um distanciamento da realidade dos alunos de Educação de Jovens e Adultos.

A professora regente da classe relatou que fazia uso de alguns livros didáticos e argumentou que era necessário utilizar vários deles, pois "não existia um livro didático que atendesse em específico a classe de jovens e adultos, daí retirava conteúdos daqui e dali para atender as necessidades".

Os livros apresentados foram os livros da coleção Viver e aprender de Português 1, Matemática e Ciências, da Editora Moderna e o livro do aluno Viver, Aprender 1, Módulos 1 e 2, da Ação Educativa. Desses, analisaram-se Português 1 e o Livro 1: Viver, Aprender (a unidade um de ambos). E procurou-se identificar dispositivos que irão produzir verdades sobre a realidade e sobre os sujeitos. Apesar da semelhança dos títulos, os 
livros são dirigidos a dois públicos distintos. A primeira coleção destina-se às crianças de $1^{\text {a }}$ Série; e o segundo, a jovens e adultos.

No livro de Português 1, os textos infantilizam o conteúdo, levando o aluno da Educação de Jovens e Adultos a uma aprendizagem acrítica, que não corresponde à proposta da justificativa do Currículo Pleno. Destacam-se dessa unidade: a forma seletiva e descontextualizada em que se trabalha o texto, a gramática e o próprio desenho. A unidade faz uso de desenhos estereotipados, tanto de animais quanto de pessoas, cuja maioria não faz parte do cotidiano. O estudo do texto, além de não favorecer ao pensamento crítico, procura extrair da criança, a quem o livro é dirigido, uma verdade sobre si mesma, fazendo-a falar de seus costumes e gostos.

Diferentemente, é o Livro 1, Módulos 1 e 2, da coleção "Viver, Aprender". Vóvio (2001), explica que os temas trabalhados do Livro 1 têm como eixo temático a identidade dos alunos, ou seja, identificam as pessoas, suas histórias e modo de vida, o espaço de vivência, o corpo.

Observando a Unidade 1 desse módulo percebe-se que ela apresenta a proposta de trabalhar com a identidade do aluno. Na página inicial apresentam-se duas questões a serem respondidas: Quem sou eu? Quem somos nós?

A unidade em questão irá trabalhar com práticas que são comuns à alfabetização de modo geral e não só a jovens e adultos, ou seja, levantar a identidade do aluno, falar de si e reconhecer seu próprio nome, identificando-o dentro do conjunto das letras do alfabeto. As questões levantadas nessa página e seguintes objetivam levar ao aluno da Educação de Jovens e Adultos a contar sua história de vida. O intuito não é apenas dar a voz a ele, mas que se reconheça enquanto fala, subjetivando-o e ao mesmo tempo sujeitando-o ao seu próprio discurso.

Aqui é possível perceber o que Larrosa (2002), Deacon e Parker (2002) observam quanto à experiência de si. Depreende-se que o aluno, ao apresentar-se à professora e a seus colegas está se expondo, falando de si, 
aquilo que gostaria de ser ou o que gostariam que ele fosse. O discurso elaborado pelo aluno, nesse caso, sujeita-o a si mesmo, conforme pensa Foucault ao referir-se ao sujeito.

Os conteúdos presentes nessas duas unidades dos livros e as práticas propostas remetem a justificativa do Currículo Pleno para a Educação de Jovens e Adultos, documento esse que propõe uma série de ações que devem ser mobilizadas pelo professor e enfatiza a necessidade de o educador levar em conta a realidade do aluno, valorizar sua experiência, além de propor conteúdos que sejam "significativos, cientificamente construídos, ter funcionalidade, considerando-se as capacidades dos alunos, suas possibilidades cognitivas e afetivas" (GOIÁS, SEE, 2001).

Apesar de esse documento evidenciar a importância da contextualização dos conteúdos e valorizar a experiência do aluno, não discute a constituição do próprio saber disciplinar dos conteúdos, nem aqui e nem em instâncias superiores. Nesse sentido, considera-se o conteúdo disciplinar como um saber legítimo, isento de qualquer disputa de poder, para se estabelecer enquanto tal. A esse respeito, Varela ao considerar os saberes pedagógicos e sua articulação, que levam a pedagogização dos conhecimentos, afirma que "a pedagogia racionaliza, em geral, uma certa organização escolar e certas formas de transmissão sem questionar nunca a arbitrariedade dessa organização, nem tampouco o estatuto dos saberes que são objetos de transmissão" (VARELA, 2002, p.93).

Outra questão é a prática metodológica da professora regente ao utilizar duas coleções opostas, tanto no que se refere ao público a que se destinam quanto aos próprios métodos propostos. A distância entre o que é proposto pelo Currículo Pleno e o que é realmente desenvolvido em sala de aula poderia ser chamada de currículo oculto, mas não deixa de ser aquilo que caracteriza o currículo, um território de lutas entre poder e saber, um jogo de verdades que produz identidades. 


\section{Algumas possibilidades para a Educação de Jovens e Adultos numa visão pós-critica}

A proposta de uma Educação de Jovens e Adultos, numa visão póscrítica, levaria em conta o sujeito não do ponto de vista humanista, como aquele que deve ser conscientizado para sua emancipação, porém, um sujeito descentrado, construído com base em discursos que produzem suas diferentes identidades. Também seriam problematizados os regimes de verdade circulantes, estabelecidos pelas disciplinas incluídas no currículo, ou seja, tais disciplinas e seus diversos saberes estariam presentes sem hierarquização. Da mesma forma, nas relações horizontais, entre alunos e professor, passar-se-ia a perceber nelas as relações de poder presente, de "forma capilar"; poder esse que também leva ao saber e é por isso mesmo positivo. As relações de poder acontecem porque também têm o seu lado positivo, produtivo, transformador.

Segundo Foucault (2001a, p. 8) "o que faz com que o poder se mantenha e que seja aceito é simplesmente que ele não pesa só como uma força que diz não, mas que de fato ele permeia, produz coisas, induz ao prazer, forma saber, produz discurso".

Com o fim das metanarrativas, o conhecimento materializado no currículo estaria mais atento às questões locais e específicas, considerando as vozes e as narrativas de cada grupo social, cultural, religioso, sexual até então desconsiderados.

A realidade educacional e, principalmente, a Educação de Jovens e Adultos, diante da mudança paradigmática que se apresenta, é complexa e nos apresenta desafios. Entendemos que não existem soluções prontas e acabadas como até então estávamos acostumados a acreditar. Faz-se necessário uma postura crítica diante da pluralidade de concepções que circulam entre nós, para que possamos refletir sobre a nossa prática educadora e decidir que rumo tomar. 


\section{Referências bibliográficas}

ANPED (2002). Educação: manifestos, lutas e utopias. GT: Educação de jovens e adultos. $25^{\mathrm{a}}$ reunião, Caxambu, $\mathrm{MG}$.

CARLOS, Erenildo João (2002). O discurso sobre a EJA: uma possibilidade de análise na perspectiva foucaultiana. In: VASCONCELOS, José Geraldo; MAGALHAES JUNIOR, Antonio Germano (Orgs.). Um dispositivo chamado Foucault. Fortaleza: LCR, p. 79-111.

COSTA, Marisa Vorraber (Org.) (1998). Educação popular hoje. São Paulo: Loyola.

DEACON, Roger; PARKER, Ben (2002). Educação como sujeição e como recusa. In: SILVA, Tomas Tadeu (Org.). O sujeito da educação: Estudos foucaultianos. 5. ed. Petrópolis: Vozes. p. 97-110.

FOUCAULT, Michel (2001a). Microfísica do poder. 16. ed. Organizador Roberto Machado. Rio de Janeiro: Graal.

FOUCAULT, Michel (2001b). Vigiar e punir: o nascimento da prisão. 24 . ed. Tradução Raquel Ramalhete. Petrópolis: Vozes.

GOIÁS, SEE. Portaria n 3914 de 28 de maio de 2001. Autoriza o funcionamento do Colégio Municipal Dona Venância Magalhães Cotrim para ministrar Educação de Jovens e Adultos e aprova Regimento Escolar, Síntese do Currículo Pleno e as Matrizes Curriculares da Unidade Escolar.

GORE, Jennifer M. (2002). Foucault e Educação: fascinantes desafios. In: SILVA, Tomaz Tadeu (Org.). O sujeito da educação: estudos foucaultianos. 5. ed. Petrópolis: Vozes, p. 9-20

LARROSA, Jorge (2002). Tecnologias do Eu e educação. In: SILVA, Tomaz Tadeu (Org.). O sujeito da educação: estudos foucaultianos. 5. ed. Petrópolis: Vozes, p. 35-86.

LAVILLE, Christian; DIONNE, Jean (1999). A construção do saber: manual de metodologia da pesquisa em ciências humanas. Tradução Heloísa Monteiro e Francisco Settineri. Porto Alegre: Editora Artes Médicas Sul Ltda; Belo Horizonte: Editora UFMG, 1999.

SOARES, Leôncio José Gomes (2001). As políticas de EJA e as necessidades de aprendizagem dos jovens e adultos. In: RIBEIRO, Vera Masagão (Org.). Educação de jovens e adultos: novos leitores, novas leituras. Campinas: Mercado de Letras, Associação de Leitura do 
Brasil(ALB); São Paulo: Ação Educativa. (Coleção Leituras no Brasil). p. 201-224.

SILVA, Tomaz Tadeu da (2001). Documentos de identidade: uma introdução às teorias do currículo. 2. ed. Belo Horizonte: Autêntica.

(1999). O currículo como fetiche: a poética e a política do texto curricular. Belo Horizonte: Autêntica.

VARELA, Júlia (2002). O estatuto do saber pedagógico. In: SILVA, Tomaz Tadeu (Org.). Sujeito da educação: estudos foucaultianos. 5. ed. Petrópolis: Vozes, p. 87-96

VERÍSSIMO, Mara Rúbia Alves Marques (1997a). Pós-modernidade e iluminismo: crítica à sociologia modernista. Revista Educação e Filosofia, Uberlândia, v. 11, n. 21 e 22, p. 163-180, jan./jun. e jul./dez.

(1997b). Os desafios da pós-modernidade à pedagogia. Ensino em Re-Vista. Uberlândia, v. 1, n. 5, p. 23-44, jul. 1996/jun. 1997.

VIVER, APRENDER (1998). Educação de jovens e adultos (Livro 1) Cláudia Lemos Vóvio (coordenação); [ilustrações de Cecília Esteves]. São Paulo: Ação Educativa; Brasília: MEC.

VÓVIO, Cláudia Lemos (2001). Viver, aprender: uma experiência de produção de materiais didáticos para jovens e adultos. In: RIBEIRO, Vera Masagão (Org.). Educação de jovens e adultos: novos leitores, novas leituras. Campinas: Mercado de Letras, Associação de Leitura do Brasil (ALB); São Paulo: Ação Educativa, p.125-136 (Coleção Leituras no Brasil). 


\section{Autora}

\section{Elizabeth Gottschalg Raimann}

Professora de Didática e formação de professores. Estágio Supervisionado na Educação Infantil e anos iniciais do Ensino Fundamental do Curso de Pedagogia da Universidade Federal de Goiás - Campus Jataí.

elizabethraimann@yahoo.com.br

\section{Como citar este artigo:}

RAIMANN, Elizabeth Gottschalg. O currículo e a educação de jovens e adultos: espaço de poder-saber. Revista ACOALFAplp Acolhendo a Alfabetização nos Países de Língua portuguesa, São Paulo, ano 2, n. 3, 2007. Disponível em: <http://www.mocambras.org> e ou <http://www.acoalfaplp.org >. Publicado em: setembro 2007. 